\title{
Seasonal Genetic Structure Analysis of a Resident Population of European Robin
}

\author{
Domenico Fulgione*, $^{*}$, Daniela Rippa ${ }^{2}$, Emanuela Manganiello ${ }^{2}$, Maria Filomena Caliendo ${ }^{2}$ and \\ Rakesh K. Rastogi ${ }^{1}$ \\ ${ }^{I}$ Department of Structural and Functional Biology, University of Naples Federico II, Monte Sant'Angelo Campus, \\ 80126 Naples, Italy \\ ${ }^{2}$ Department of Biological Sciences, University of Naples Federico II, via Mezzocannone 8 - 80134 Naples, Italy
}

\begin{abstract}
This study is based on the microsatellite DNA analysis of 160 birds from the resident population of the European robin (Erithacus rubecula) in South Italy. It used assignment procedures to study population genetic structure on a seasonal and spatial scale. This population undergoes, twice each year, an altitudinal and intraregional short-distance migration. The present analysis corroborates inference on short-distance altitudinal migratory phenomenon in a resident robin population and suggests that the resident population investigated by us is "faithful" to its intraregional breeding and wintering areas. Our data further indicate that the resident population may represent a distinct genetic entity and suggest that regional ecological features along this geographical area as well as some behavioural characteristics of birds may concur in the maintenance of population separation.
\end{abstract}

Keywords: Erithacus rubecula, population genetic structure, phenology, microsatellite.

\section{INTRODUCTION}

The European robin (Erithacus rubecula) is a small passerine bird that breeds in higher and mid-latitudes of the Western Palearctic [1, 2]. Like other passerine species, the European robin shows a variegated pattern of movements in the non-breeding period. There are long-distance migrating populations of robins in Europe and there are other populations, generally in sourthern Europe, that only migrate short distances between their breeding and wintering grounds $[3,4$, 5]. The latter populations are referred to as resident populations in this manuscript. Continental Europe, including the entire Mediterranean area, is traversed by at least four allohiemic robin populations that differ from each other in the geographical location of their winter quarters and migration routes as well as in migration timing [6]. These long-distance migrants make brief stop-overs, to rest and refuel, in the Mediterranean basin.

An adjacent area of the Palinuro Peninsula in South Italy (ca. $350 \mathrm{~km}$ south of Rome) is an important stop-over site, to rest and refuel in spring, for one of the long-distance migratory robin populations. Notably, in this area there are resident populations of robin that breed in the mountain and winter in the adjacent river valley and coastal area (our unpublished data under the guidance of late Prof. M. Milone) [7]. Ringing, as standard monitoring technique, has demonstrated that such resident robins exhibit strong fidelity to there wintering and breeding territories as well in North and South Italy [8] as in several other localities of the Mediterranean basin $[9,10,11]$.

*Address correspondence to this author at the Department of Structural and Functional Biology, University of Naples Federico II, Monte Sant'Angelo Campus, Via Cinthia, 80126 Napoli, Italy; Tel: +39 081679177; Fax: +39 081678210; E-mail: fulgione@unina.it
What may have caused the presence of several extant resident populations of the European robin along the Mediterranean basin has been discussed by several researchers $[12,13,14$, $15,16,17,18,19]$. These studies suggest that early occupation of the most suitable feeding areas during wintering by some long-distance migratory populations may have induced them to remain and become resident populations. Although still a matter of active debate as to how and why, such geographically-defined resident robin populations do persist despite the annual arrival in such areas of relatively large numbers of long-distance migrant conspecifics. The migrant conspecifics may cause a substantial population-admixture with resident populations during the migratory periods [20].

Studies of this sort require the recognition of individual birds of a given population at each capture. Bird migration and bird population dynamics have been studied by a variety of techniques of which ringing is undoubtedly the oldest and probably the most common. Colour marking, use of radar, radio- and satellite tracking and use of stable hydrogen isotopes are some of the newer techniques employed in such studies [21]. Some of these methods are based on the recognition of single individuals whose morphological characters (such as body size, body mass, wing length) become part of the whole scheme in making population structure analysis. The availability of some recent molecular techniques allows genetic fingerprinting of single individuals. Such techniques are non-invasive and represent a highly efficient tool to reconstruct complex population structures, parental relationships and geographical dispersion or aggregation.

The objective of the present study was to assess the population genetic structure of the European robin across a resident population in a small, geographically well-defined, area in South Italy (Cilento Mountain range, Mingardo river valley 
and estuary within the Cilento \& Vallo di Diano National Park). It has been verified repeatedly, by ringing methods, that the European robin populations in Campania Region primarily display altitudinal and short-distance migration, mountain-valley-mountain. During their total absence in the mountain breeding area, they are seen in an adjacent valley/coastal area. The Mingardo river valley area was selected because it is here that the majority of individuals from the mountain breeding population descend for wintering and the long-distance migrant conspecifics make a stop-over during their North-bound migration in spring (Fig. 1). Within the study area breeding population gathers at an altitude of approximately 900 meters or more and the wintering population settles at near sea level in the river valley and the contiguous coastal area. The investigated area therefore provides an interesting situation to study population structure on a seasonal scale and to compare genetic diversity, if any, between mountain and Mingardo River Valley residents. In the present study we used polymorphic microsatellite markers (extracted and purified from a single feather from each robin) and assignment procedures to investigate gene flow and population structure of E. rubecula at two different spatial scales within a fragmented mountain-valley landscape. This study will complement previous morphological and population survey work and may provide evidence for any genetic admixture between individuals of the resident population and the long-distance migrant conspecifics of the European robin.

\section{MATERIAL AND METHODOLOGY}

\section{Study Area and Sampling Strategy}

During the years 2005 and 2006 we sampled a resident population from the breeding (mountain - ca. $900-1200 \mathrm{~m}$ altitude) and wintering grounds. Sampling locations are shown in Fig. (1). E. rubecula is endemic to the region and is not classified as vulnerable; nonetheless, our study was conducted under the necessary authorizations. We mist-netted, measured and ringed a total of 160 robins in the study area belonging to the Cilento \& Vallo di Diano National Park in South Italy, using standard protocol of identification [22]. Only adult birds (males and females) were used in this study. A single feather was plucked from each bird for the extraction of genomic DNA. These robins undertake short distance migration, twice-a-year, in response to changing photoperiod and seasonal surplus or scarcity of food (unpublished data) [23]. During the breeding period (May - July) practically all resident birds move to the mountains of Cilento, at an altitude of approx. $900-1200 \mathrm{~m}$. Sixty of these adults $(\mathrm{M} ; n=60)$ were sampled in an area of approx. $105 \mathrm{~km}^{2}$, between late June and early July 2005 . We define the breeding robins sampled by us as a population because it is a large group of individuals separated from the neighbouring breeding groups by deep and large valleys. In autumn the mountain population descends in the nearby valley and its contiguous coastal area of the National Park. Valley- and coastal area-dwelling robins were sampled in a ca. 5-km X 6-km area, at the end of Octo-

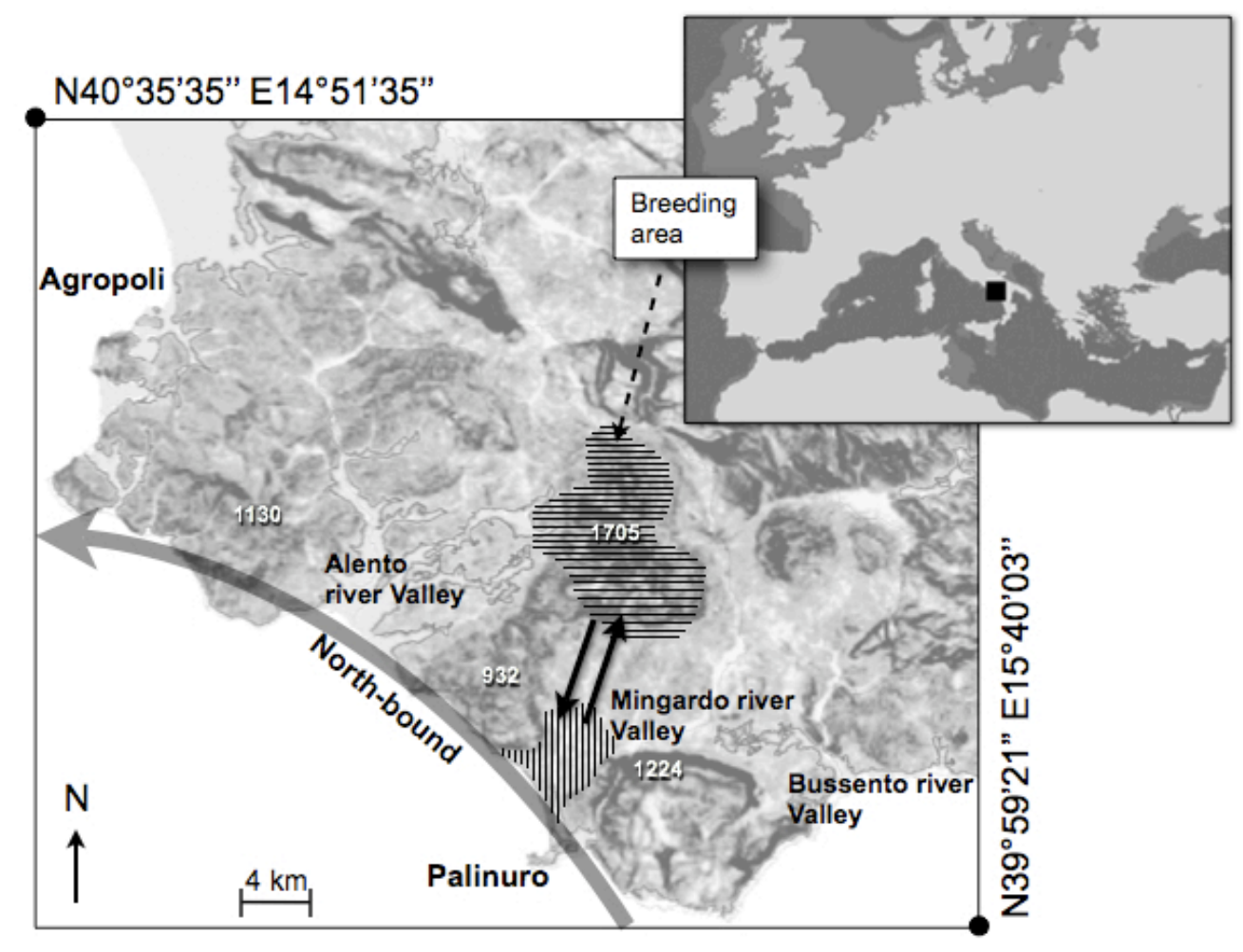

Fig. (1). Geographical location of the Cilento \& Vallo di Diano National Park in South Italy. Sampling areas are shown by vertical hatching (wintering area) and horizontal hatching. The main altitudinal short-distance migratory movements of the resident population studied by us is shown by black arrows. Grey arrow indicates the North -bound stream of the long-distance migrant conspecifics. 
ber $2005\left(\mathrm{~V}_{\mathrm{O}} ; n=20\right)$ as well as in late March - early April $2006\left(\mathrm{~V}_{\mathrm{A}} ; n=20\right)$ when the long-distance migrant conspecifics flock in this area. Sampling in December $2005\left(\mathrm{~V}_{\mathrm{D}} ; n=\right.$ 20), January $2006\left(\mathrm{~V}_{\mathrm{J}} ; n=20\right)$ and February $2006\left(\mathrm{~V}_{\mathrm{F}} ; n=\right.$ 20) covered the typical wintering months of this species in Campania Region of Italy.

For the field preservation of feathers we used a preservation solution (20\% DMSO, 25\% EDTA $0.25 \mathrm{M} \mathrm{pH} 8.0$ ) saturated with $\mathrm{NaCl}(5 \mathrm{M})$ and thymol in traces. Birds were released after ringing, body measurements and feather sample collection.

\section{Genetic Characterization}

Genomic DNA was extracted from each feather by using Chelex (Bio-Rad) synthetic resins. DNA extraction was processed according to Taberlet and Bouvet with some minor modifications [24]. Each feather was cut transversely from the base; this was cut longitudinally and put in a tube for digestion with proteinase K. Digestion was carried out overnight at $50^{\circ} \mathrm{C}$ with gentle shaking in $5 \%$ Chelex 100 . Each digested sample was vortexed and again incubated at $80^{\circ} \mathrm{C}$ for $10 \mathrm{~min}$ in Chelex. Subsequently, the sample was centrifuged at $13.000 \mathrm{rpm}$ to separate supernatant from Chelex spherules. The upper phase was filtered through a Bio-101 tube to eliminate Chelex residuals and then utilized for PCR amplification after quantification.

Microsatellite analysis was performed on six polymorphic loci. The flanking region of microsatellites may be retained in closely related taxa [see $25,26,27,28]$ and as such, microsatellite primers developed for one species may be useful for amplification and analysis of other species. In this heterologous amplification, the primers annealing probability in the retained loci decreases as evolutionary distance between the examined species increases [27, 29]. Ten microsatellite couples of primers were screened and only six of these, related to six polymorphic loci, were selected: Ck.1B5D and Ck.4A3G described in Corvus kubary [30]; LOX1 and LOX2 described in Loxia scotica [31]; HrU2 and HrU7 described in Hirundo rustica [27].

PCR amplification was performed in a final reaction volume of $25 \mu \mathrm{l}$ containing $85 \mathrm{ng}$ of genomic DNA and $0.5 \mu \mathrm{l}$ of each primer $(1 \mu \mathrm{M})$. Each reaction mixture included $1 \mathrm{U}$ of Taq polymerase, PCR buffer $\left(160 \mathrm{mM}\left(\mathrm{NH}_{4}\right)_{2} \mathrm{SO}_{4} ; 670 \mathrm{mM}\right.$ Tris-HCl pH 8.8); $15 \mathrm{mM} \mathrm{MgCl}_{2} ; 0.1 \%$ Tween $20,0.2 \mathrm{mM}$ dNTP and $2 \mathrm{mM} \mathrm{MgCl}_{2}$. All PCRs were performed in an Ep- pendorf thermocycler. Amplification thermal profile for each microsatellite primer was tested and standardized. PCR conditions for Ck.1B5D and Ck.4A3G involved annealing at $50^{\circ} \mathrm{C}$; for primers LOX1 and LOX2 involved annealing at $54^{\circ} \mathrm{C}$; for primers $\mathrm{HrU} 2$ and $\mathrm{HrU} 7$ involved annealing at $55^{\circ} \mathrm{C}$. Each reaction ended with a final 5-min extension at $72^{\circ} \mathrm{C}$. In order to verify the presence of tandem repeat, the amplification products were purified with Amersham PCR purification kit and sequenced using the BigDye ${ }^{\mathrm{TM}}$ Terminator Cycle Sequencing chemistry (Applied Biosystem ${ }^{\mathrm{TM}}$ product) protocols. The sequences were recorded with an ABI3100 automated sequencing instrument (PerkinElmer ${ }^{\mathrm{TM}}$ ). For the detection and sizing of allele fragments, one primer from each pair was end-labeled with a fluorescent dye (FAM and HEX, MWG Biotech ${ }^{\mathrm{TM}}$ ) and each microsatellite locus was screened with capillary electrophoresis in ABI3100.

\section{Elaboration}

Pair-wise linkage disequilibrium was computed using Linkage Disequilibrium test for all pairs of loci [32]. Population genetic structure was analyzed in several ways: the level of variation using mean number of allele (MNA), expected heterozygosity $(\mathrm{He})$, observed heterozygosity (Ho) per population and pair-wise genetic differences [33,34]. These analyses were done with ARLEQUIN version 2.0 [35]. Patterns of differentiation were visualized by a Factorial Correspondence Analysis (FCA) of individuals' multilocus score using GENETIX version 4.04 [36]. This multivariate analysis is based on a $\chi^{2}$ value computed by comparing the observed distribution of alleles in genotypes with that expected if alleles were randomly assigned to individuals. The computed $\chi 2$ were elaborated and assigned to genotypes, and usually only the first two variables were plotted [37, 38].

An identification of population affinity of individual samples was done using STRUCTURE version 2.1 [39, 40], assuming no prior information, the admixture model with correlated alleles, and a burn-in phase of 10000 iterations followed by a run phase of 100000 iterations. The number of populations $(\mathrm{K})$ ranging from 2 to 13 was tested in three independent runs to establish consistency. The posterior probability was then calculated for each value of $\mathrm{K}$ to chose the most likely $\mathrm{K}$. We also used a model with essentially the same parameters as earlier, but providing prior information of population membership, to identify immigrants if any, or in-

Table 1. Genetic Diversity in the Valley Temporal Populations (V) and Mountain Breeding Populations (M)

\begin{tabular}{|c|c|c|c|c|c|c|}
\hline Population & N & MNA(SE) & Lower & Upper & He(SD) & Ho(SD) \\
\hline \hline $\mathrm{V}_{\mathrm{O}}$ & 20 & $3.33(0.42)$ & 2.24 & 4.41 & $0.440(0.2)$ & $0.480(0.2)$ \\
\hline $\mathrm{V}_{\mathrm{D}}$ & 20 & $3.66(0.33)$ & 2.80 & 4.52 & $0.347(0.3)$ & $0.507(0.2)$ \\
\hline $\mathrm{V}_{\mathrm{J}}$ & 20 & $4.50(1.38)$ & 0.94 & 8.05 & $0.479(0.2)$ & $0.634(0.1)$ \\
\hline $\mathrm{V}_{\mathrm{F}}$ & 20 & $3.33(0.49)$ & 2.06 & 4.60 & $0.333(0.2)$ & $0.453(0.2)$ \\
\hline $\mathrm{V}_{\mathrm{A}}$ & 20 & $2.16(0.16)$ & 1.73 & 2.59 & $0.142(0.1)$ & $0.250(0.2)$ \\
\hline $\mathrm{M}$ & 60 & $4.53(1.89)$ & 0.19 & 9.52 & $0.487(0.1)$ & $0.653(0.1)$ \\
\hline
\end{tabular}

MNA: mean number of allele, SE: standard error, He: expected heterozygosity, Ho: observed heterozygosity., SD: standard deviation. Lower and Upper $95 \%$ confidence interval is reported. 
Table 2. Pair-Wise Conventional F-Statistics from Temporal Groups in the Valley (V) and Breeding Population in the Mountain (M)

\begin{tabular}{|c|c|c|c|c|c|c|}
\hline & $\mathbf{V}_{\mathbf{O}}$ & $\mathbf{V}_{\mathbf{D}}$ & $\mathbf{V}_{\mathbf{J}}$ & $\mathbf{V}_{\mathbf{F}}$ & $\mathbf{V}_{\mathbf{A}}$ & \\
\hline \hline $\mathrm{V}_{\mathrm{O}}$ & - & & & & \\
\hline $\mathrm{V}_{\mathrm{D}}$ & $0.047^{*}$ & - & & & \\
\hline $\mathrm{V}_{\mathrm{J}}$ & $0.055^{*}$ & 0.000 & - & - & \\
\hline $\mathrm{V}_{\mathrm{F}}$ & $0.076^{*}$ & 0.008 & $0.031^{*}$ & $0.136^{*}$ & $0.086^{*}$ & - \\
\hline $\mathrm{V}_{\mathrm{A}}$ & $0.170^{*}$ & $0.118^{*}$ & 0.007 & 0.000 & $0.111^{*}$ & \\
\hline $\mathrm{M}$ & $0.054^{*}$ & 0.004 & 0. & - \\
\hline
\end{tabular}

*indicates significant distance level, $P<0.05$.

dividuals who have recent immigrant ancestry [34]. This approach is a powerful tool to analyze population admixture when it is suspected that some samples might have contributed to the genetic composition of the "admixed" population.

\section{RESULTS AND DISCUSSION}

All six microsatellite loci were polymorphic, with the mean number of alleles per locus being to the tune of 3.58 (Table 1). Comparatively, however, in the sample of 20 individuals collected in the month of April in Mingardo river valley the number of alleles was the least variable and that of the breeding $(\mathrm{M})$ and January wintering $\left(\mathrm{V}_{\mathrm{J}}\right)$ samples the most variable. Similarly, the expected heterozygosity across all samples was variable and ranged from 0.142 to 0.487 (mean $=0.370 \pm 0.18$ ). Population-level and global tests of linkage disequilibrium failed to detect the instances of significant linkage among the six microsatellite markers in the majority of individuals. Genetic diversity analysis shows high genetic variability as inferred from the rather high mean values of allele numbers and heterozygosity, particularly high among individuals of the breeding population (M) and among those collected in high winter $\left(\mathrm{V}_{\mathrm{J}}\right)$ (Table 1). Among all samples, the lowest genetic variability was observed in the $\mathrm{V}_{\mathrm{A}}$ (valley, April) sample.

The pair-wise genetic distance values (using Fst; ARLEQUIN version 2.0) are relatively high between the mountain breeding population $(\mathrm{M})$ and the April valley sample $\left(\mathrm{V}_{\mathrm{A}}\right.$ and $\mathrm{V}_{\mathrm{O}}$ ) when the long-distance migratory individuals might have become a part of the sample (Table 2). In contrast, these values are comparatively lower among the breeding $\mathrm{M}$ sample and the wintering December, January and February valley $\left(\mathrm{V}_{\mathrm{D}}, \mathrm{V}_{\mathrm{J}}, \mathrm{V}_{\mathrm{F}}\right)$ samples. Highest such values were observed for the $\mathrm{V}_{\mathrm{A}}$ sample as compared to all other samples, i.e., $\mathrm{M}, \mathrm{V}_{\mathrm{F}}$, $\mathrm{V}_{\mathrm{J}}, \mathrm{V}_{\mathrm{D}}, \mathrm{V}_{\mathrm{O}}$ (Table 2).

By plotting the individual scores, the genotype factorial analysis (Fig. 2) shows that practically all individuals sampled from the mountain breeding population are clustered in a central portion of the $\mathrm{X}$ - and $\mathrm{Y}$-axis crossing. Individual scores from all bird samples of the valley population during

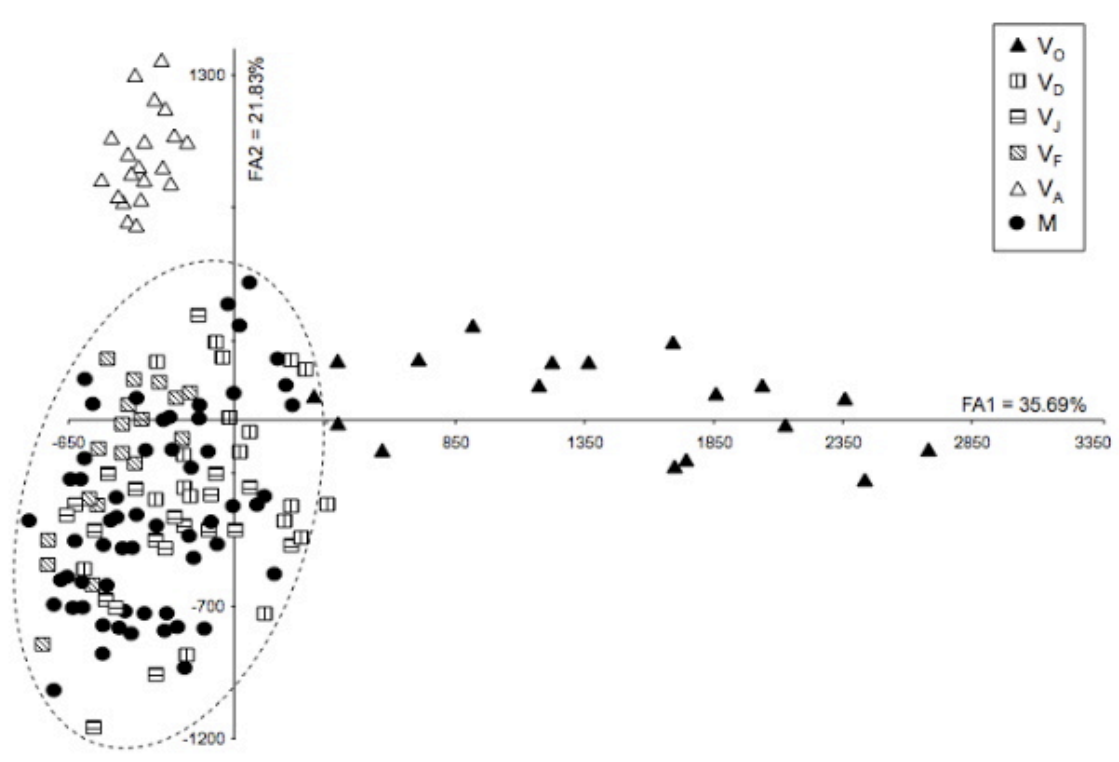

Fig. (2). Factorial Correspondence Analysis of the 160 individual genotypes. Symbols indicate the different spatial and temporal samples. 
Table 3. Assignment analysis with Bayesian clustering approaches. The number of clusters is indicated by $\mathrm{K}$. Probability of the data is in the Ln, probability of $\mathrm{K}$ clusters column and the variance of the probability is presented in the variance Ln column. Alpha values $(\alpha)$ indicate the admixture value

\begin{tabular}{|c|c|c|c|}
\hline K & Ln probability of K clusters & Variance Ln & 0.1010 \\
\hline \hline 2 & -1256.3 & 64.7 & 0.0656 \\
\hline 3 & -1228.1 & 171.1 & 0.0541 \\
\hline 4 & -1175.5 & 230.4 & 0.0488 \\
\hline 5 & -1147.0 & 299.5 & 0.0477 \\
\hline 6 & -1148.9 & 371.5 & 0.0436 \\
\hline 7 & -1158.9 & 448.1 & 0.0315 \\
\hline 8 & -1186.0 & 570.1 & 0.0399 \\
\hline 9 & -1170.5 & 653.3 & 0.0390 \\
\hline 10 & -1226.6 & 709.5 & 0.0390 \\
\hline 11 & -1271.5 & 726.1 & 0.0382 \\
\hline
\end{tabular}

the winter months $\left(\mathrm{V}_{\mathrm{D}}, \mathrm{V}_{\mathrm{J}}, \mathrm{V}_{\mathrm{F}}\right)$ also cluster within this area as shown in Fig. (2). However, individual genotype scores from $\mathrm{V}_{\mathrm{A}}$ and $\mathrm{V}_{\mathrm{O}}$ are distinct and they cluster separately, respectively along the $\mathrm{Y}$-axis and the $\mathrm{X}$-axis, well apart from each other and from the rest of the groups (Fig. 2).

In the assignment analysis with Bayesian clustering approach, structuring of the data was performed by inferring different numbers of genetic clusters $(\mathrm{K})$ or populations ranging from $K=2$ to $K=13$ (Table 3 ). The probability of the number of populations $(\mathrm{K})$ was estimated in each case (Ln: probability of data) without using any prior population information so that each individual was assigned to a cluster based upon its multilocus genotype profile. The admixture parameter $(\alpha)$ detected with $\mathrm{K}$ value was also estimated. Data was obtained from six population samples, from the mountain and the river valley area. Of these, birds in the mountain made one sample, whereas in the valley they were sampled in five different months. The highest probability of the data ( $\mathrm{Ln}=-$ 1147.0; $\alpha=0.0488$; Table 3) was found with clusters set at 5 . Instead, the lowest $\alpha$ value was found with cluster set at 8 (Table 3). This suggests that the number of clusters defined by allele frequencies is lower than 8 but higher than 5 . By $\mathrm{K}$ $=6$ analysis, some individuals become strongly assigned to one of the six inferred groups (i.e., genetic population clusters). The genetic contribution (y-axis) of each inferred group or cluster (shown by colours) into the individual genotype is shown in the histogram (Fig. 3). Each bar corresponds to one individual genotype.

In general, in all samples there were individuals that were assigned genetically to cluster \#1 (eighteen out of sixty in the mountain sample, and six, four, two, four and eight respectively in the October, December, January, February and April sample). Comparatively fewer individuals were assigned to the genetic cluster \#5 but only from the breeding sample and from that collected in January. Genetic cluster \#3 was repre- sented only in the breeding and October samples, whereas only four individuals in December sample were assigned to the genetic cluster \#4. No individual from the whole lot of animals investigated showed assignment probabilities of greater than $60 \%$ for the genetic cluster \#6 (Fig. 3). In the April sample, twelve robins, out of twenty, were assigned genetically to the cluster \#2 with assignment probabilities and posterior probabilities of greater than $50 \%$. No other individual in any other period or area of sampling was assigned to this cluster (Fig. 3).

In the mountain breeding population an average of $47 \%$ of the individuals could not be assigned to any of the genetic cluster. Similarly, in October, December, January and February samples there occurred a highly variable percentage of individuals not assigned to any cluster being, respectively $40 \%, 75 \%, 70 \%$ and $80 \%$. Only in the April sample $100 \%$ of the individuals could be assigned to a genetic cluster (Fig. 3). In this sample, a $60 \%$ proportion was assigned to a source, most likely the long-distance migrant conspecifics. In fact, in April 2006, there occurred a conspicuous flooding of the sampling area on part of the long-distance migrant conspecifics; interestingly, in this sample it was observed that twelve out of twenty individuals showed a genetic assignment probability of $60 \%$ to a cluster (\#2) to which no other individual from any other sample was assigned, a fact that might corroborate their status as migrants.

It seems that this population does not experience significant gene flow during the invasion of its feeding grounds on part of the long-distance migrant conspecifics. In the April sample, the high value of pair-wise genetic distance suggests an apparent separation between the short- and long-range populations.

Our data are also suggestive of the existence of loop migration for the long-distance migrants which is consistent with the probability assignment results clearly showing the 


\section{PROPORTION OF INDIVIDUAL MEMBERSHIP}

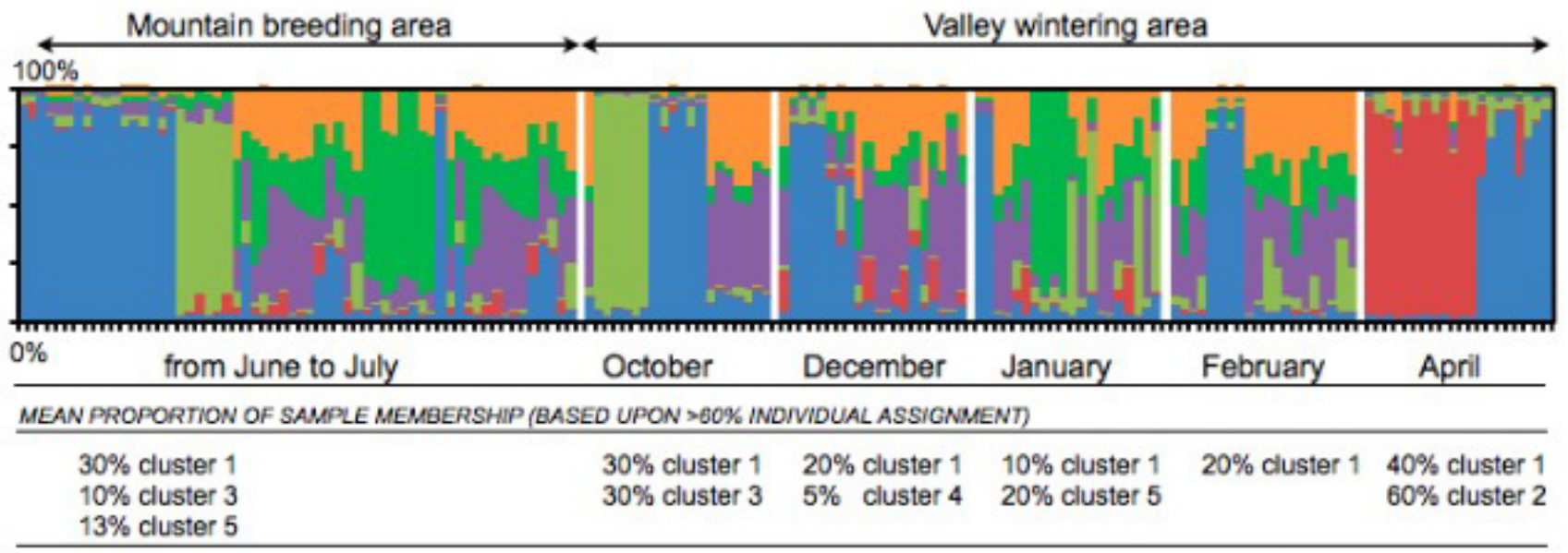

cluster 1

cluster 2

cluster 3

cluster 4

cluster 5

cluster 6

Fig. (3). Genetic Clustering assignment by STRUCTURE version 2.1. In the bar plot, individuals are grouped according to sampling month and each of the 160 individuals is represented by a vertical bar indicating its estimated proportion of assignment to each genetic cluster. Genetic population clusters are coded with different colours and the fraction of colour for each individual represents the probability of assignment to the cluster with that colour. Under the bar plot is indicated the mean proportion of assignment of each sample to each cluster where individuals with greater than $60 \%$ assignment to a cluster are counted.

appearance of a genetic cluster entirely different only in the April sample. The long-distance migrants are required to make this stop-over to refuel and store energy while migrating to their Northern breeding grounds; short-distance migrants return to their breeding grounds directly without calling at any intermediate stop-over site. This population can be considered located in a putatively "isolated" Mediterranean area and it apparently shows evidence of only restricted gene flow with other nearby populations.

Relatively high levels of genetic diversity in the mountain sample (M) and a valley sample $\left(\mathrm{V}_{\mathrm{J}}\right)$ makes it plausible that they are part of the same breeding population where gene flow appears high. Wthether and to what extent there could be out-breeding type of gene flow is not possible to analyze.

From a population perspective, each of the samples examined in this study may together represent a population that may be predominantly self-recruiting having a quite similar genetic composition. It can be argued that there is a relatively high level of within population gene flow which is sufficient to prevent within population divergence. From our data we can not determine explicitly whether there is any genetic admixture between long-distance migrants and local individuals. Bigger and repeated sampling is required to clarify this point. It may be expected that such "isolated" populations may have high in-breeding levels and increased genetic differentiation with the neighbouring populations. It is also plausible that though our population and the neighbouring populations are practically isolated from each other during wintering because of the presence of high peaks between valleys, there is in all probability some gene flow when these birds return to the breeding areas high up in the mountains.

Could the presence of a mountain range between the river valleys be considered a significant barrier to movement of birds from one valley to the other during wintering? It would signify that resident birds from different nearby river valleys, all separated by high peaks, will remain isolated from each other and as such the genetic structure of any one of these populations could maintain its identity without any significant gene flow from outside (except perhaps on part of the longdistance migrants; but these migrants usually make a brief stop over and then go away). Further investigations are required to fill these lacunae in our understanding of the population dynamics in a geographical area where there are more than one resident populations that are separated by physical barriers during wintering. As yet, all statistical methods utilized here for inferring phenology dectected the occurrence of a local population conservation.

In the end, the data on population genetic structure becomes a useful source of information for future management plans. Further studies on some neighbouring populations are warranted.

\section{ACKNOWLEDGMENTS}

The logistic and financial supports from the University of Naples Federico II and Cilento \& Vallo di Diano National Park of Italy are acknwledged.

\section{REFERENCES}

[1] Cramp S. The Birds of Western Palaeartic, Ed. Oxford, Oxford University Press, 1996.

[2] Read M. The robin. Blandford Press, London, 1992.

[3] Biebach H. Genetic determination of partial migration in the European Robin (Erithacus rubecula). Auk 1983; 100: 601-606.

[4] Berthold P. Bird migration: a general survey. Oxford Univ. Press, Oxford, 1993.

[5] Blondel J, Aronson, J. Biology and wildlife of the Mediterranean Region. Oxford University Press, 1999. 
[6] Remisiewicz M. The spatio-temporal pattern to Robin Erithacus rubecula migration - evidence from ringing recoveries. Ardea 2002; 90: 489-502.

[7] Lovei GL, Scebba S. Wintering site fidelity of the Robin Erithacus rubecula and the Dunnock Prunella modularis on a Southern Italian island. Proceeding of the XVII Congress of the Hungarian Biological Society; 1986: Szeged, Hungary: Hungarian Biological Society 1987; p. 68.

[8] Benvenuti S, Ioalè P. Fedeltà al luogo di svernamento in anni successivi, in alcune specie di uccelli. Avocetta 1980; 4: 133-139. [in Italian].

[9] Herrera CM, Rodriguez M. Year-to-year site constancy among three passerine species wintering at a Southern Spanish locality. Ring Migr 1979; 2: 160.

[10] Cuadrado M. Year to year recurrence and site-fidelity of Blackcaps (Sylvia atricapilla) and Robins (Erithacus rubecula) in a Mediterranean wintering area. Ring Migr 1992; 13: 36-42.

[11] Schaub M, Liechti F, Jenni L. Departure of migrating European robins, Erithacus rubecula, from a stopover site in relation to wind and rain. Anim Behav 2004; 67: 229-237.

[12] Andriansen F, Dhondt AA. Population dynamics and partial migration of the European robin (Erithacus rubecula) in different habitats. J Anim Ecol 1990; 59: 1077-1090.

[13] Cuadrado M. Why are migrant robins Erithacus rubecula territorial in winter? The importance of the anti-predation behaviour. Ethol Ecol Evol 1997; 9: 77-88.

[14] Tobias J. Asymmetric territorial contests in the European robin: the role of settlement costs. Anim Behav 1997; 54: 9-21.

[15] Johnstone I. Territory structure of the robin Erithacus rubecula outside the breeding season. Ibis 1998; 140: 244-251.

[16] Pérez-Tris J, Carbonell R, Tellería JL. Identificación e importancia poblacional de los Petirrojos Erithacus rubecula locales durante la invernada en el sur de España. Ardeola 2000; 47: 9-18.

[17] Tellería JL, Pérez-Tris J, Ramírez A, Fernández-Juricic E, Carbonell R. Distribution of Robins (Erithacus rubecula) in wintering grounds: effects of conspecific density, migratory status and age. Ardea 2001; 89: 363-373.

[18] Pérez-Tris J, Tellería JL. Regional variation in seasonality affects migratory behaviour and life-history traits of two Mediterranean passerines. Acta Oecol 2002; 23: 13-21.

[19] Catry P, Campos A, Almada A, Cresswell W. Winter segregation of migrant European robins Erithacus rubecula in relation to sex, age and size. J Avian Biol 2004; 35: 204-209.

[20] Tellería JL, Pérez-Tris J. Consequences of the settlement of migrant European robins Erithacus rubecula in wintering habitats occupied by conspecific residents. Ibis 2004; 146: 258-268.

[21] Berthold P. Bird migration: A general survey. 2nd Ed. Oxford: Oxford University Press 2001.

[22] Svensson L. Identification Guide to European Passerines. Stockholm 1992.

[23] Berthold P. Migration, birds. In Encyclopedia of Reproduction. Ed. E. Knobil and J.D. Neill. Academic Press, San Diego 1998; Vol 3 : 228-233.
[24] Taberlet P, Bouvet J. A single plucked feather as a source of DNA for bird genetic studies. Auk 1991; 108(4): 959-960.

[25] Menotti-Raymond M, O'Brien SJ. Evolutionary conservation of ten microsatellite loci in four species of Felidae. J Hered 1995; 86: 319 322.

[26] Angers B, Bernatchez L. Usefulness of heterologous microsatellites obtained from brook char, Salvelinus fontinalis Mitchill, in other Salvelinus species. Mol Ecol 1996; 5: 317-319.

[27] Primmer CR, Moller AP, Ellegreen H. Resolving genetic relationships with microsatellite markers: a parentage testing system for the swallow Hirundo rustica. Mol Ecol 1996; 4: 493-498.

[28] Steinkellner H, Lexer C, Turetschek E, Glössl J. Conservation of (GA)n microsatellite between Quercus species. Mol Ecol 1997; 6 : 1189-1194.

[29] Moore SS, Sargeant LL, King TJ, Mattick JS, Georges M, Hetzel DJS. The conservation of the dinucleotide microsatellites among mammalian genomes allows the use of heterologous PCR primer pairs in closely related species. Genomics 1991; 10: 654-660.

[30] Tarr CL, Fleischer RC. Primers for polymorphic GT microsatellite isolated from the Mariana crow, Corvus kubaryi. Mol Ecol 1998; 7 : 247-255.

[31] Piertney SB, Marquiss M, Summers R. Characterization of tetranucleotide microsatellite markers in the Scottish crossbill (Loxia scotica). Mol Ecol 1998; 7: 1247-1263.

[32] Slatkin M, Excoffier L. Testing for linkage disequilibrium in genotypic data using the EM algorithm. Heredity 1996; 76: 377-383.

[33] Weir BS, Cockerham CC. Estimating F-statistics for the analysis of population structure. Evolution 1984; 38: 1358-1370.

[34] Michalakis Y, Excoffier L. A generic estimation of population subdivision using distances between alleles with special references to microsatellite loci. Genetics 1996; 142: 1061-1064.

[35] Schneider S, Roessli D, Excoffier L. Arlequin 2.0: a software package for population genetics data analysis. Genetics and Biometry Lab, Department of Anthropology, University of Geneva 2000.

[36] Belkhir K, Borsa P, Chikhi L, Raufaste N, Bonhomme F. GENETIX 4.04 Logiciel sous Windows ${ }^{\mathrm{TM}}$ pour la Génétique des Populations. Laboratoire Génome, Populations, Interactions: CNRS UMR. 5000. Université de Montpellier II, Montpellier 2001.

[37] Randi E, Pierpaoli M, Beaumont M, Ragni B, Sforzi A. Genetic identification of wild and domestic cats (Felis silvestris) and their hybrids using Bayesian clustering methods. Mol Biol Evol 2001; 18 : 1679-1693.

[38] Vernesi C, Crestanello B, Pecchioli E, et al. The genetic impact of demographic decline and reintroduction in the wild boar (Sus scrofa): A microsatellite analysis. Mol Ecol 2003; 12: 585-595.

[39] Pritchard JK, Stephens M, Donnelly P. Inference of population structure using multilocus genotype data. Genetics 2000; 155: 945 959.

[40] Evanno G, Regnaut S, Goudet J. Detecting the number of clusters of individuals using the software STRUCTURE: a simulation study. Mol Ecol 2005; 14: 2611-2620.

(C) Fulgione et al.; Licensee Bentham Open.

This is an open access article distributed under the terms of the Creative Commons Attribution License (http://creativecommons.org/licenses/by/2.5/), which permits unrestrictive use, distribution, and reproduction in any medium, provided the original work is properly cited. 